\title{
Chapter 9 \\ Emotion Regulation of Others and Self (EROS) During the COVID-19 Pandemic
}

\author{
Andrew M. Lane \\ Faculty of Education, Health and Well-Being, University of Wolverhampton, UK
}

Please cite as: Lane, A. M. (2021). Emotion regulation of others and self (EROS) during the COVID-19 pandemic. In Z. Zenko \& L. Jones (Eds.), Essentials of exercise and sport psychology: An open access textbook (pp. 200-218). Society for Transparency, Openness, and Replication in Kinesiology. https://doi.org/10.51224/B1009

\section{CC-By Attribution 4.0 International}

This content is open access and part of Essentials of Exercise and Sport Psychology: An Open Access Textbook. All other content can be accessed at https://doi.org/10.51224/B1000

\section{Chapter Overview}

By March $1^{\text {st }} 2021$, the COVID-19 pandemic caused over 2.5 million deaths worldwide. To restrict spreading of the virus, movement was restricted. At the outbreak of the pandemic, there were concerns for poor mental health in both the immediate and long-term future. Encouraging people to use strategies to regulate the emotions of others and self is therefore worthwhile. In this chapter, I look at how the pandemic affected emotion and the use of emotion regulation strategies guided by the Gross and Thompson (2007) five-family model. Strategies people typically used were often not available or easy to do in lockdown, and so careful planning was necessary. A reflective case study that describes an emotion regulation strategy via a physical challenge is described. The case study outlines how setting an exciting challenge and how sharing progress can influence the emotions of others and self. In summary, active planning of emotion regulation strategies that you do is worth considering for managing emotions and mood, which help maintain positive mental health. 


\section{Introduction: COVID-19, Emotions, and Emotion Regulation}

In 2020, COVID-19 was a new virus, with no known cure or antidote. On March 23, 2020, the UK government implemented a national lockdown to try to prevent the virus spreading to reduce the risks of mass deaths. The measures implemented included banning non-essential travel, closing pubs, restaurants and theatres. The effects on employment were equally dramatic. People were asked to work from home unless they were an essential worker, where examples of jobs included those working in hospitals, the police, armed forces, shop keepers, supermarkets, travel and firefighters. People with underlying health conditions, over the age of 75 years, and pregnant women were also told to minimise social contact for 12 weeks.

At the outbreak of the pandemic, poor mental health, negative mood, and intense negative emotions were expected consequences (Maclntyre et al., 2020; Restubog et al., 2020). Evidence shows such fears materialised. In a study of 17,685 people in China, Wang et al. (2020) reported an increase in anxiety and depression. Based on such findings and theoretical predictions, advising people to actively use emotion regulation strategies to help manage mental health is sensible advice. At the outset of the pandemic, a special issue by the journal Frontiers called for articles for a special issue.

\section{Learning Exercise One}

Look at the articles in the special issue on COVID-19, select one article and read it in-depth. I authored one article on mood states in boxers (Roberts \& Lane, 2021); evaluate the strategies used by boxers with reference to Gross and Thompson's (2007) model.

In this chapter, I encourage people to identify and evaluate the use of self-regulation strategies. People naturally self-regulate (Bandura, 1997; Carver \& Scheier, 1990). If people have strategies that they believe will work and can self-regulate effectively this alleviates a great amount of pressure on mental health services. This approach sits well with advice from key members of the Scientific Advisory Group for Emergencies (2020), whose model for behavioural change was based around the capability, motivation, and opportunity to keep others and oneself safe during the pandemic (West et al., 2020).

\section{Learning Exercise Two}

Think back to the start of the Pandemic, and what were your initial responses to hearing the restrictions? The aim of this exercise is to engage in reflection on your experiences at the start of COVID-19. Try to identify thoughts and feelings in relation to imposed restrictions. The following headings might be useful.

What occurred:

What are your reflections?

Thoughts and feelings:

What happened:

Reflection on thoughts: 
At the outbreak, in my role of being a sport psychologist practitioner, I had athletes experiencing intense emotional responses such as anxiety and uncertainty. As 2020 started, athletes had hopes and goals focused on athletic achievement and in the space of a few weeks, these goals were put on hold. Athletes needed to be patient and see out the pandemic. It should not be surprising that athletes did not have the experience to deal with such rapid and unexpected changes (see Carruthers, 2020). I recently discussed the importance of emotion and emotion regulation in the work of practitioners (Lane, 2020) where awareness of one's own emotions and how they might transmit to others should be considered. Evidence suggests how current emotional state influences relative positivity or negativity to future hopes, where a positive emotional state associates with feeling hopeful (Schubert et al., 2020). In this chapter, I examine self-regulation in the COVID-19 crisis through a case study. I focus on emotion regulation of others and self. I will outline key theoretical issues before going through the case study to illustrate how theory applies to practice.

\section{Emotions and Emotion Regulation}

Emotions are subjective feelings experienced in response to events either in an individual's environment, for example, a boxer climbing into a boxing ring or a surgeon going into theatre, or in an individual's mind, for example, anticipation of an upcoming event. For example, if either a boxer or a surgeon thought about the contest or surgery coming up and was concerned about the outcome, then they are likely to experience an increase in the intensity of their emotions. Emotions encompass three types of response (Lazarus, 2000):

1) Emotions include physiological responses such as increased respiration and heart rate. Although the intensity of a physiological response is a key part of emotion, it is very difficult to identify an emotion from physiological measures alone, and especially in tasks where movement is involved. A perception of physiological states was a positive feature of research into competitive anxiety (Marten et al., 1990), although this approach did not extend to other emotions or areas of application other than sport. Evidence suggests that failed attempts to regulate intense emotions associated with a disturbed physiological response (Beedie et al., 2012; Lane, Wilson, et al., 2011) possibly due to challenges in selfcontrol (Gailliot et al., 2007). When regulating emotions, self-awareness of physiological changes is important and at times, focusing directly on the physiological responses is necessary (Thompson \& Gross, 2007). At the outset of the COVID-19 pandemic, a sense of fear of being exposed to situations where you could catch COVID-19 coupled with no reliable and proven self-regulation strategies to cope (these were soon learned) meant that focussing on managing the physiological aspects of emotion was a useful skill.

2) Emotions include cognitive changes such as attention, perception, and information processing priorities. Emotions influence what information comes to mind and how we might feel at a later point in time (Baumeister et al., 2007). The ongoing changes in cognition as people attempt to regulate their current emotional state is relevant. For example, during COVID-19, if you are anxious about catching the virus, then the thought of visiting the shops could intensify these anxious feelings. Further, the thought of transmitting the virus to loved ones could contribute to anxiety further. It could also lead to shame and sorrow if you thought you passed the virus onto another person via an act of carelessness. The COVID-19 crisis raised the intensity of anxiety, and this can prompt a search of the environment to identify the cause of the issue, something that is difficult as you cannot see a virus. In this instance, anxiety is likely to prompt adherence to behavioural advice such washing hands and social distancing (West et al., 2020). As I later point out, if you are running, people attempt to get out of your way and look anxious; seeing people become anxious is not something runners are used to, and so this changes the nature of the run. If you are running to improve mood, then seeing your actions negatively impact other people's emotion has the reverse effect. 
3) The third aspect of emotion is behavioural such as increasing the intensity of behaviour to actively pursue a goal. Behavioural change could be directed to raise or to conserve energy. For example, anxiety and anger can provide a flight or fight response whereas depression promotes a response that conserves energy. Emotional energy can help people attain their goals with numerous studies showing positive relationships between emotions and performance. This has been evidenced in goal achievement in sport (Beedie et al., 2000; Han et al., 2020) and goal achievement in work settings (García-Buades et al., 2020). Recent work has developed models on how emotion regulation could operate in achievements settings (Harley et al., 2019). Identifying emotional profiles associated with success and failure has been a challenging line of investigation with a great deal of evidence pointing towards an ideographic model as the best explanation (Han et al., 2020; Hanin, 2010; Lane, 2012a). What this means is that for people to be able to effectively regulate their emotions, they need to know what emotions help them perform well. Evidence shows that many people accept experiencing unpleasant emotions before trying to achieve important goals, and learn to interpret these feelings as ready to perform. In other words, they use the energy developed by unpleasant emotions to raise arousal, and via increased arousal, effort increases (Lane, Beedie, Devonport, \& Stanley, 2011). If emotional profiles cannot be linked to success, then it begs the question as to how an individual knows whether they should try to increase or decrease the intensity of any given emotion. In keeping with the idiographic approach, knowledge of how emotion influences your actions is an important aspect of selfawareness (Lane, 2012a; Lane, Beedie et al., 2012). From those meta-beliefs, it is possible to have a personal database of how to interpret emotional states and decide whether to try to amplify, dampen, or maintain the intensity of a given emotion. Clearly, this process works well when there is a good knowledge of the emotions required for successful performance. In COVID-19, where the situation was new and unclear, the bank of experiences on which to base meta-beliefs was shallow as the outbreak began and developed via learning.

\section{Learning Exercise Three}

Reflect on your emotional experiences. Select one, and then close your eyes and think back to when you were experiencing it. What did you hear? What did you feel? Immerse yourself in the experience. Now try to identify

1) What feelings did you experience?

2) What thoughts occurred?

3) What physiological changes occurred?

It is important to consider all physiological, cognitive, and behavioural responses together. Via these three types of response, emotions influence the goals people establish, their intentions and choices to attain them, and their behaviour (Baumeister et al., 2007). Baumeister et al. (2007) argued that emotions have powerful effects and we monitor emotions via self-regulatory processes. We identify how we feel in comparison to how we want to feel. How we want to feel can depend on the task we are doing. When we anticipate or experience emotions we dislike, we seek strategies to regulate the intensity of these feelings. A key aspect is that we regulate to an internal standard of how we wish to feel, although when we ask people how they wish to feel we do not always get precise answers (Beatty \& Janelle, 2020). Of available evidence we have, it should not be surprising that unpleasant emotions feature highly (Hanin, 2010; Lane, 2012a), and when people experience emotions such as shame, sadness, and misery they could seek actions to down regulate the intensity of these emotions. 
Emotion regulation is the automatic or deliberate use of strategies to initiate, maintain, modify or display emotions (Gross \& Thompson, 2007; Gross \& Feldman-Barrett, 2011). Ongoing self-regulation of emotions can not only help regulate emotions to improve feelings, but also help people achieve goals. For example, the emotions of anger and fear, which are unpleasant and intense could drive strategies to regulate these emotions to deal with the causes of them (the "fight or flight response", see Nesse \& Ellsworth, 2009). However, emotion regulation attempts might be dysfunctional. For example, an athlete might be angry about having to run alone or not be able to train at the gym, and the expression of this emotion might be an angry response focused toward people they live with, creating an unhappy mood, meaning that the negative emotion lasts longer than it should. Devonport and Lane (2013) showed how couples can regulate their own and each other's emotions.

In terms of how people regulate their emotions, studies indicate that people organically use conscious and non-conscious strategies to regulate their emotions with over 400 strategies identified (Augustine \& Hemenover, 2008; Koole, 2009; Thayer et al., 1994). For example, talking to people, watching television, going out for meals, playing sport, listening to music, are all tasks that people identify with as part of day-to-day living, and when prompted to reflect on how they aid emotional wellbeing cite them as effective strategies (Thayer et al., 1994). In terms of a theoretical model, Gross and Thompson (2007) developed a five-family model which specifies that people regulate their emotions by selecting the situation they are placed in (situation selection), how they might change the situation (situation modification), what they choose to concentrate or focus on (attentional deployment), how they modify their thoughts and as such select information to focus on that changes their emotion (cognitive change) or how they try to modify the physiological responses or try to squash the effects of the emotions (response modulation). Four of these families of regulation (situation selection, situation modification, attentional deployment, and cognitive change) can be used before the emotion has become fully blown with response modulation being used once the emotion is intense and warrants regulation. A key feature of emotion regulation is that many strategies are not exclusively emotion regulation strategies, but when asked how people regulate their emotions, people recognise the link between the actions and their feelings. On recognising these links, an individual learns to identify that using the strategy can bring about changes in emotions, thereby creating a conscious link. And so, of course, the restrictions placed during COVID-19 meant many of these strategies could not be used.

\section{Learning Exercise Four}

How do you regulate your emotions? Think back to when you have experience intense emotions, what did you do? How long did the emotion last? Write down as many actions or thoughts as possible. There are no right or wrong answers. It will help identify what you do to alter your emotions.

After doing this, consider what a sport psychologist might do if presented with a person presenting these emotions and describing how they regulate them. And so, imagine yourself as the sport psychologist where you are also the client.

\section{Emotion Regulation Strategies During COVID-19}

I will illustrate how the five-families (Gross \& Thompson, 1997) of the model could be applied during COVID-19.

Situation selection refers to the process whereby you actively choose to place yourself in one situation rather than another. As previous research has illustrated, there are a range of strategies people 
use. People can self-select situations to alter emotions, for example: the decision to meet friends in a cafe, to go to the theatre, to go for a run, to watch a funny film, or to go on holiday. It is likely that people do not explicitly see these as emotion regulation strategies, but when asked to think about what they do, they report doing such activities (Thayer et al., 1994). When we asked athletes the same questions, they responded in a similar way (Stevens \& Lane, 2001; Terry et al., 2006). During lockdown, some of these strategies became more difficult to do. For people living in close conditions, where people could only go out of their house for one hour for exercise or shopping, then being in close proximity to others would be very restrictive. In such conditions, it is likely people will experience increased anxiety and frustration. For people trying to exercise alone, the restricted choice of possible activities available creates concerns. For people used to running, there was a possibility of running outside for an hour. At the start of the lockdown, runners raised concern that they would be seen running outside twice in one day and were conscious of avoiding possible arguments with neighbours who might observe them. For people who regularly used gyms, which were closed, the ability to train required equipment and the speed the virus spread was so fast that sports equipment was sold out, and if not sold out, delivery of sports materials was restricted. A challenge was to find ways to exercise although there were a plethora of celebrities running exercise sessions via social media.

As the lockdown in the UK began, we wrote an article that encouraged people to exercise and use green environments to help manage mood (Maclntyre et al., 2020). We encouraged people to use the strategy savouring when getting into nature was not easy. There is a growing evidence base on the therapeutic effects of being in nature, and the notion that exercising in nature has additive effects (Lahart et al., 2019). Savouring is done by using images from prior experiences in nature to remind yourself of previous positive experiences and feelings. The restrictions on movement and social interaction meant that people became consciously aware of not being able to change location very easily and often who they were with. Conscious awareness of what emotion regulation strategies is argued to be a key reason why they are effective (Custers et al., 2019; Lane, 2012a). Knowing what you wish to use, but not being able to use them has negative effects. Therefore, to effectively use situation selection with a self-regulatory framework is to be aware of the options available, to know what factors are readily available to change and what are not.

The second approach is situation modification which refers to attempts to modify external aspects of the environment. For example, if you recognise your mood needs regulating, that is you wish to cheer yourself up, or stop yourself feeling anxious, then deciding to modify your situation is a good strategy. Many strategies had to be modified due to the requirements for keeping safe during COVID-19. If people ran or cycled to help manage emotion and did so alone or with a member of their own house, then they could continue. People who ran with training groups felt the impact of the new restrictions as people could not meet to go running. Evidence shows the benefits of exercising in groups via social benefits where people support each other and performance benefits. Performing with others can build confidence via reflections on performance creating the mindset "if they can do it, so can I" (Bandura, 1997). The impact of COVID-19 meant that people needed to re-think what they could and could not do (Roberts \& Lane, 2021), and this additional act of thinking and planning could be tiring (Gailliot et al., 2007). Repeated acts of self-control are proposed to be tiring, and although there is some dispute on this theory (Inzlicht \& Friese, 2019), COVID-19 did serve to disrupt automated habits.

The third strategy is attention deployment which refers to the process whereby an individual directs their attention to influence their emotions, and with COVID-19 restrictions this strategy could be used, for example, planning your training. For example, making a conscious decision on what to focus on. With COVID-19, where running outside brought unusual interactions from others due to the new need for distancing (see Carruthers 2020, who details her experiences) and so runners who are used to 
focusing internally on running are made more aware of others, and so change their normal routines. Runners needed to plan sessions so that they had little potential contact with others.

Attention deployment is often used when it is difficult to change or modify the situation. Attentional deployment could be done in the form of distraction, for example, deciding to listen to music when exercising and focusing on the music. When running during the early stages of COVID-19, as Carruthers (2020) points out, there was a sense that people were looking and thinking "why is this person running when we should be in lockdown?", and if such a thought went through your mind, it could create unpleasant emotion. And so, focusing on listening to music can be helpful. Attentional deployment can perpetuate unpleasant emotions via rumination, and so repeatedly focusing on potentially negative events in the future serves to maintain the intensity of the emotion.

\section{Learning Exercise Five}

Go through the five families of emotion regulation and give an example from personal experience of how you have used them.

- Situation selection

- Situation modification

- Attention deployment

- Cognitive change

- Response modulation

Now repeat this task as if you are working with an athlete. Go through the five families and consider how you might use them.

In the COVID-19 crisis, where normality shifted, active planning was desirable and therefore planning your training could enable situation selection and modification strategies being achieved by appropriate planning. The fourth approach is cognitive change which involves changing the meaning of an event or situation, and with COVID-19, this can be useful as priorities shifted via aggressive messaging to stay home/save lives meant a re-think of many actions previously seen as normal. Spending some time to re-think these and so avoiding frustrations at not being able to do them can prevent unpleasant emotions arising. Examples of cognitive change include distancing or taking a thirdperson perspective when evaluating an emotional event and thereby being able to gain an in-depth reflection. Humour is an example of cognitive change, and by having a goal to make yourself and others laugh it is possible that this has wider benefits.

The fifth approach is response modulation. The other four emotion regulation strategies are anticipatory, whereas response modulation is used once the emotion has been experienced fully. Response modulation refers to strategies designed to regulate the physiological and cognitive aspects of emotion as directly as possible. Regulating the physiological arousal associated with emotion makes intuitive sense in sport given that optimal arousal levels will vary substantially between sports, from the low arousal associated with sports such as archery to high arousal in sports such as powerlifting. Regulating strategies include progressive muscular relaxation, centring, imagery, listening to music and exercise (see Karageorghis et al., 2011; Lane, 2012a).

In summary, the COVID-19 crisis intensified the emotions in many people and simultaneously also influenced the availability of strategies to regulate emotions. This combined effect can explain an increase in poor mental health and why people should be encouraged to plan to use emotion regulation 
strategies. Consistent with theoretical proposals, prevention of unpleasant emotions is better than cure (Gross \& Thompson, 2007). To illustrate how this can happen, I will use a case study of an emotion regulation strategy used in COVID-19.

\section{Case study}

From the outset it should be emphasized that this a reflective piece of work on emotion regulation during the unique situation of a pandemic. The goal of writing this particular case study was to illustrate the key issues. Reflection is a key part of a researcher and practitioner's work and so should be treated accordingly (Devonport \& Lane, 2013). In terms of the options I considered, I developed a case study of work with athletes which articulates my effort to maintain their motivation, of which gave me good first-hand insight into how the stresses and strains of a pandemic affect high-performing individuals. I collected daily mood data on this athlete which details the intensity and severity of emotions experienced. Within this case study, I could talk about strategies that were used to maintain training and emotional health. Running concurrently, I supported several athletes, and the work produced similar findings, that emotions became unpleasant, normal regulation strategies were harder or suspended, social challenges were more difficult. Maclntyre and colleagues (2020) detail some of this work. The summary of this work was that I was seeing trends in emotional response that were similar to what was observed in other case studies that focused on emotions experienced in stressful challenges (Devonport et al., 2011; Lane \& Godfrey, 2010; Lloyd, Pedlar, Lane, \& Whyte, 2007). Our book on case studies (Lane, Godfrey, et al., 2014) provides many examples for practitioners, hence I was keen to do something different. Our article that details experiences going through In-Vitro-Fertilization (Devonport \& Lane, 2013) which the author (Devonport) was also a participant, and my article on experiencing from boxing (Lane, 2006), and my recent chapter on emotions practitioner's feel, were all influential in my decision. I decided to use myself as the target of the case study. I further thought, as the chapter will reveal, this could be suitable as from the outset I set out on a programme of activities that were designed to maintain positive emotions in myself and others.

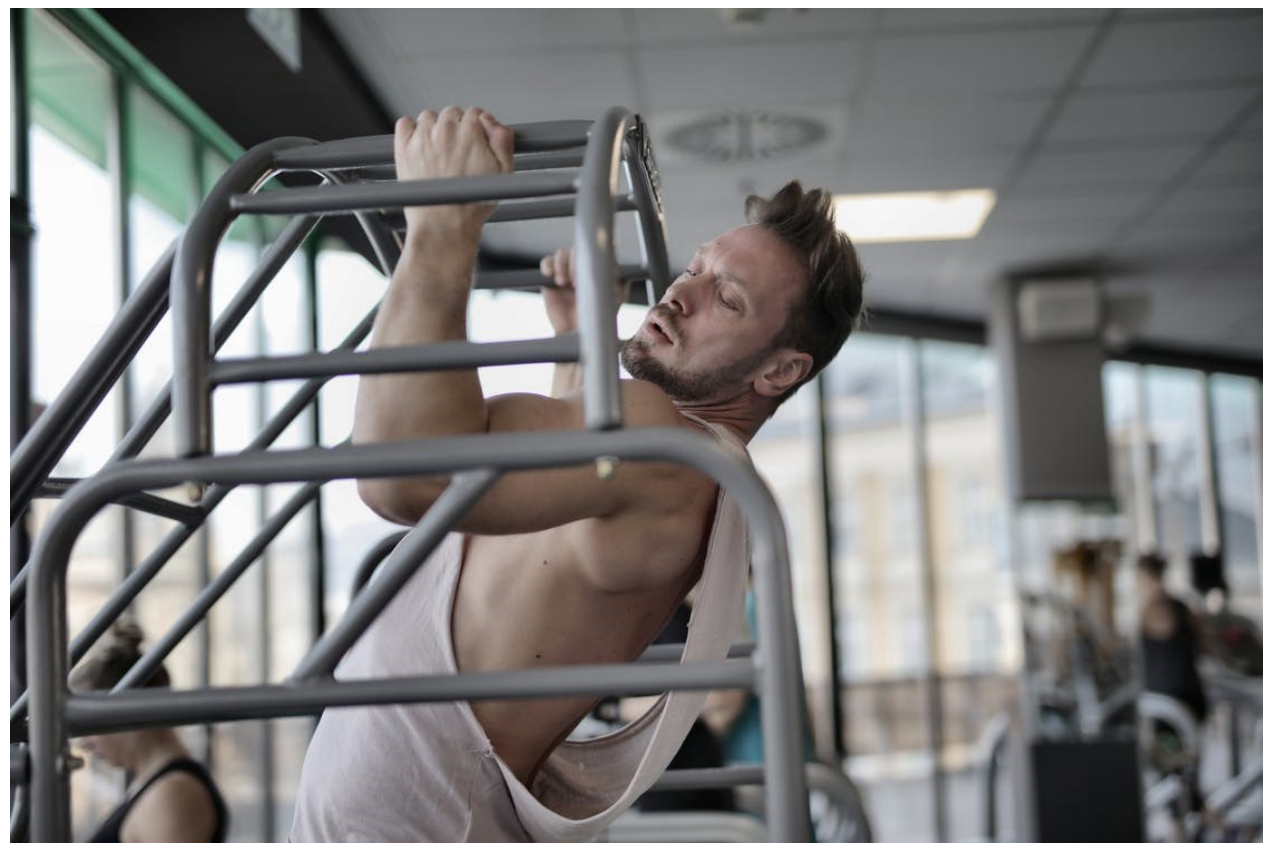

Photo by Andrea Piacquadio from $\underline{\text { Pexels }}$ 


\section{Case Study on Emotion Regulation: "Keeping Your Chin Up By Doing Chin Ups"}

Prior to lockdown, my life would involve going to work, which is a $15 \mathrm{~km}$ (Walsall campus) or $40 \mathrm{~km}$ (Wolverhampton Campus) drive depending on which campus I was attending. Each week I ran a $5 \mathrm{~km}$ parkrun, amassing 451 parkruns since October 2011, which shows how few weeks were missed. At parkrun, we have a group of friends whom we would meet and have coffee with after the run. I had started indoor rowing, partly as a response to a knee injury, and had competed in indoor competition and would go to a leisure centre most evenings. In those evenings, we would have coffee and meet people. My wife, who has run a similar number of parkruns, would come to the gym with me most evenings; and the act of going to do exercise in varying formats was a major aspect of our social life. I detailed in a chapter how exercise can be used to regulate emotions with the idea that you could "run yourself happy" (Lane, 2012b). Lockdown, of course, changed this approach to emotion regulation with all of these stopping overnight as gyms closed, parkrun suspended, and all events I had entered being cancelled. Competitive events such as parkrun have more than an exercise function; they create a time and place to raise the intensity of high-active emotions and make use of anxiety and unpleasant emotions (Lane, Beedie et al., 2012; Stanley, Lane, et al., 2012; Stanley, Beedie, et al., 2012).

I had been watching how the spread of the virus was unfolding in France and Spain, where leisure facilities closed three-weeks ahead of the UK, and so bought a Concept2 rowing machine for use at home (the Concept 2 is seen as the gold standard for indoor rowing and used by Olympians and by a large online indoor rowing community), clearing a room out, meaning I disposed of two sofas. They were put to the side of the house initially and later permanently removed, thereby to illustrate that we had sufficient space and were not having to overcome cramped living conditions. The huge change to my living conditions was easier because my wife shared these goals; had the situation been different, then this course of action would have an adverse effect. If my actions upset my wife, then the social aspect of emotion regulation means that her emotions influence me, and therefore, further thought is needed.

As we went into lockdown, the emotion regulation I used would not be possible. I felt I needed a challenge and running in preparation for the return of races seemed too distal, and importantly, I had little control over when this would occur. Being a sport psychologist, and advocate of promoting mental health through physical activity, active across social media and a regular media commentator, I felt the message of encouraging people alone to be active would be shallow and lack meaning; that is, I should practice what I preach! Further, I felt it needed to be contextualised in the current situational constraints. This is an important aspect of any self-regulation attempt in that the person doing it needs to see the task as suitably worthwhile to do. The self-regulation strategy was to be a behavioural goal. When setting a goal, it needs to captivate interest to be effective; a key reason why goal setting is effective is that they direct attention and motivation. I saw this as an opportunity to promote mental health through doing physical activity and simultaneously doing something to manage my own mental health.

In considering the options, I wanted a challenge that was largely under my control. Perceived control and a strong sense of autonomy is argued to be an important aspect of sustaining behavioural change (West et al., 2020). At the time, the message from the UK government was that people could exercise for one-hour outside. During my initial runs, I noticed many people displaying signs of anxiety through fear of social contact. Looking at what happened in Italy and Spain around the same time, there was a possibility that all forms of going outside would be restricted. I felt the exercise should use a confined space. 


\section{Why One More Chin Up for Each Day of Lockdown?}

My decision was to do one chin up for each day of lockdown, whereby on day one, I did one chin up, two chin ups on day two and so on until lockdown was over. I used the phrase "keeping your chin up by doing chin ups" across social media, recorded a film of me doing the chin ups, doing impersonations, and trying to create funny stories, and posted them to a YouTube channel (Lane, 2020). The plan was to perform one more chin up for each day of lockdown, and so I did a single chin up on day one going through to doing 125 chin ups on the final day. I decided lockdown had eased sufficiently with the key marker being the re-opening of gyms. The rationale for selecting the closure and opening of gyms was that I used exercise and going to the gym as a social event as one of my main emotion regulation strategies.

Before lockdown, I was doing chin ups occasionally on a morning run in the park, where there is a park gym, so I was confident I could do at least one chin up, and confident I could get through the first few days. I hoped to make progress during that time that would enable attainment of more chin ups; but the goal was specific and only one more chin up. Using self-efficacy theory (Bandura, 1997), I should have confidence to attain the target. It should be noted that the chin up facility in the park was also closed early on. I had a chin up bar on the side of my house. From the start I felt confident I could do one chin up. It was only one extra chin up and so at the point of failure, the question of whether I could do one more is consistent with a great deal of advice I have given to endurance athletes (Lane, 2012b). With endurance athletes, the advice has been to break tasks down into short units, specific goals and ones that are attainable (Lane, 2012b). The goal is achieved by holding a narrow and process-based focus of attention. I wished to test and showcase this mindset, which is something I see not only as good advice for others, but also for myself. In applying science to practice, an important aspect is the evidence that it works. My view was that I was modelling this, something I felt was useful from the role of sport psychologist, but also by doing it myself; I would be regulating my own emotions. In terms of emotion regulation, it is a case of situation selection (Gross \& Thompson, 2007) and I decided that doing the chin ups would serve many goals;

a) it was exercise, which I used daily to manage my mood, and physically challenging as I wondered how many I could do and how it would unfold;

b) it was outside, and so I could engage with nature; and

c) it was challenging, and so I sought to advertise to as many as possible, thereby increasing anxiety to some degree, which helped me commit to doing them.

Doing the chin ups presented many challenges, but it also revealed many positive aspects that were not considered at the start of the process. These include using humour and the positive effects of planning humour on your mood and on others, managing sensations of fatigue, finding time, and maintaining motivation.

\section{Humour as an Emotion Regulation Strategy}

On March 23rd, 2020, which was also my birthday, I did one chin up, filmed it on my phone and posted the film to Twitter and Facebook. The film received several thousand views daily; I became more adventurous in how I made the films. Using the Apple I-Movie suite, I would film the chin ups, adding music, narrative, pictures, and on occasions created a storyline. Watching chin ups is not something that easily makes for the best programme, and so I tried to make them funny. I did this in a variety of ways, doing impersonations of famous people (Michael Caine, Frank Spencer, Bruce Forsyth) and having a storyline. For example, on the day of the Swimathon (I had entered to do a $5000 \mathrm{~m} \mathrm{swim}$ ) I did the chin up Swimathon, doing chin ups in a swimming costume, swim hat and goggles (see Lane, 2020). 
The act of trying to make humorous material is in itself an emotion regulation strategy (Samson \& Gross, 2012). Evidence shows humour is effective and is used by people in extreme conditions where situational opportunities to alter emotions are minimal. Planning activities and scenes of a video is a creative process and you are trying to envisage material that is funny. If this is positive, and you think it could be funny, then that thought is a positive one, and you think you are making something worthwhile. The image of people smiling when watching your video is a positive one; what you are doing is modifying the situation of others, and thereby improving emotions if possible. This produces a large sense of satisfaction, which is mood enhancing.

However, acts such as pretending to be going to a swimming gala and walking out in your garden in your trunks evoke feelings of being self-conscious, and with that a fear that people are not laughing with you but at you, which brings unpleasant emotions. To manage such potentially unpleasant emotions, I engaged in the emotion regulation strategy of cognitive change (Gross \& Thompson, 1997); to change the meaning, I reminded myself that the goal was for it to be entertaining. It was important for me to recognise the multiple roles people have and that, despite this coming out under the banner of me as a sport psychologist, acting out exercise in an enjoyable way and creating as entertaining a backdrop as I could did not conflict with that image.

\section{Overcoming Fatigue-Keeping the Challenge in Perspective and Focusing on the Present}

At the start of the chin up process, I had not thought what day 30 would feel like or look like. After day seven, I knew that the chin ups would not be done in one continuous set. I started researching how to do chin ups and learning any technique that might help by looking at experts. It showed that world chin up records were carried out in a series of sets of repetitions and even the best and fittest did not do more than 10-15 chin ups in one set, typically going for multiple sets of a lower number. In the early days, my confidence to do a large number grew when I found I could repeat sets of seven repetitions. Performance accomplishments are a strong source of self-efficacy (Bandura, 1997), and a strong sense of self-efficacy is a good strategy for the management of unpleasant emotions. In Gross and Thompson's (2007) model, it is a cognitive change and beliefs to do the task, and therefore uncertainty over failure was low. The knowledge that even the very best chin up performers do not do sets over 10 repetitions that frequently, and rarely exercise to failure, provided a strategy I was confident to follow. Alongside this, I viewed many YouTube videos on how to do chin ups that focused on the skill aspect rather than only about physical fitness. This enabled breaking down chin ups into discrete movements and practicing them. For example, I practised hanging for 30 seconds, and used this practice to provide entertainment also (I sang Always Look on the Bright Side of Life from the Monty Python film The Life of Brian whilst hanging over the chin up bar one time). By having it as a part of a comedy sequence, where I sang a song and had to act happy, I also regulated physical discomfort by changing my attention. Brick et al., (2018) found that smiling during a marathon race is a good way to manage fatigue.

The comedy aspect is important. If the challenge was truly demanding to the extent that few people could do it, then that in itself is worth reporting. I have supported people doing such challenges such as riding across America, doing a channel swim (Lane \& Whyte, 2008), running the Marathon Des Sable (Lane, 2006), and the North Pole Marathon (Lane \& Devonport, 2008). A large number of chin ups is something most people would not want to do but, possibly similar to a challenge such as running a marathon, think they could do with training. I thought the same. I did not want to try to present a message that the challenge was particularly impressive; therefore, the goal was to complete the required number of chin ups, try to make the video funny via the storyline, impersonations, and by wearing fancy dress. The details and their anticipated impacts on my emotions and the emotions of others are important; via feedback on social media and requests for impersonations, the chin up videos evolved. 


\section{Finding Time}

As the number of chin ups grew, it clearly took longer to do the chin ups and make the film. In addition to this, there is a growing sense of fatigue. Once I had to do more than 80 chin ups, the number of sets and repetitions needed to be thought through carefully. In addition to this, it became an expectation that the chin up film would be published on social media in the morning. Attempting to overcome a difficult challenge is motivating; it directs attention to what is needed and as such encourages prioritising actions and resources. To develop strong self-efficacy beliefs that you can do this is about following key principles as outlined by Bandura (1997). To develop confidence in being able to do the task, I watched videos on YouTube to develop technique. What this enabled was to re-think how to approach doing the chin ups, insomuch that I focused on the skills needed as opposed to seeing it as a fitness task. This has relevance to regulating perceptions of fatigue when doing chin ups; by focusing on skill, I sought ways to make the task easier to do, which helped with a narrative on what to focus on.

\section{Being in Control}

In the COVID-19 crisis, a key point was to perceive I was in control of when and where I could exercise. I had a chin up bar and the instruction of not leaving your house meant I didn't focus on having to go out. Whilst in normal times, going out is to be encouraged, during the early stages of lockdown, when people were wary, I feel people were watching me when running. Whether this was merely my being self-conscious, it changed the quality of the experience. Added to that, there were instances where people were clearly frightened, and so being able to exercise in my home was suitable. These features are relevant to the uptake of any emotion regulation strategy. Setting challenges where contextual factors increase the size of the challenge should be an important consideration. Sedentary people who wish to exercise regularly often set a goal to exercise daily, but exactly how to do this is not clear. Having the opportunity to do the exercise makes the choice to do it is easier and having an attainable goal as to how much exercise to do helps build motivation. With the chin up exercise, the first 10 days were relatively straightforward, and so the aspect of forming the habit of doing the exercise was successful. A key issue is developing the behaviour so that the habit is formed from the performance itself-starting easy and making the progress small, one more chin per day up in this case, helped develop the mindset that it was possible. A key part of this was also to not think too far ahead. If I thought about how hard day 60 was at day 10 , this could be overwhelming. In a similar way, it is how marathon or endurance athletes are coached, that is to keep the focus on the here and now because seeing the overall size of the task can be overwhelming.

\section{Learning Exercise Six}

Open Google Scholar and use the key search terms "COVID James Gross emotion". This will give you the latest articles that use Gross's work. Compare how findings relate to one of these articles.

\section{Conclusion}

The abilities to identify current emotional states, identify how you wish to feel, possess sufficient skills, and have confidence in your ability to use these skills should be a part of the toolkit people have. COVID-19 was an assault on emotions, and, via restrictions imposed, impacted the emotion regulation strategies that could be used. The present chapter has used a case study to illustrate how emotion regulation strategies can be used and how the principles of finding an engaging task, 
which you can make progress on, can develop confidence in being able to do it. Then, via performance accomplishments, belief in abilities increases, and the habit is formed. I suggest that such a process could be applied to learning new emotion regulation strategies and that people should be encouraged to see learning emotion regulation strategies as a key goal to maintain their mental health.

\section{Further Reading}

Gross, J. J., \& Thompson, R. A. (2007). Emotion regulation: Conceptual foundations. Guilford Press. Lane, A. M. (2015). Sport and exercise psychology: Topics in applied psychology ( $2^{\text {nd }}$ edition). Taylor \& Francis.

Lane, A. M., Godfrey, R., Loosemore, M., \& Whyte, G. W (2014). Case studies in sport science and medicine. ISBN-13: 978-1499146943.

\section{Acknowledgements}

I acknowledge the support of Dr Helen Lane who enjoyed watching the first version of each of 125 Keeping Your Chin Up videos.

\section{References}

Augustine, A. A., \& Hemenover, S. H. (2008). On the relative effectiveness of affect regulation strategies: A meta-analysis. Cognition and Emotion, 23, 1181-1220. https://doi.org/10.1080/02699930802396556

Bandura, A. (1997). Self-efficacy: The exercise of control. Freeman.

Baumeister, R. F., Vohs, K. D., DeWall, C. N., \& Zhang, L. (2007). How emotion shapes behavior: Feedback, anticipation, and reflection, rather than direct causation. Personality and Social Psychology Review, 11, 167-203. https://doi.org/10.1177\%2F1088868307301033

Beatty, G. F., \& Janelle, C. (2020). Emotion regulation and motor performance: An integrated review and proposal of the Temporal Influence Model of Emotion Regulation (TIMER). International Review of Sport and Exercise Psychology, 13, 266-296. https://doi.org/10.1080/1750984X.2019.1695140

Beedie, C. J., Lane, A. M., \& Wilson, M. G. (2012). A possible role for emotion and emotion regulation in physiological responses to false performance feedback in 10 mile laboratory cycling. Applied Psychophysiology and Biofeedback, 37(4), 267-277. https://doi.org/10.1007/s10484-012-9200-7

Beedie, C. J., Terry, P. C., \& Lane, A. M. (2000). The Profile of Mood States and athletic Performance: Two meta-analyses. Journal of Applied Sport Psychology, 12, 49-68. https://doi.org/10.1080/10413200008404213

Brick, N., McElhinney, M. J., \& Metcalfe, R. S. (2018). The effects of facial expression and relaxation cues on movement economy, physiological, and perceptual responses during running. Psychology of Sport and Exercise, 34, 20-28. https://doi.org/10.1016/j.psychsport.2017.09.009

Carver, C. S. (2004). Self-regulation of action and affect. In R. F. Baumeister, \& K. D. Vohs (Eds.), Handbook of self-regulation: Research, theory and applications (pp. 13-39). Guilford Press.

Carruthers, H. (2020). Running with the COVID19 chaos. https://www.youtube.com/watch?v=LQ9uQseBinc

Custers, R., Vermeent, S., \& Aaarts, H. (2019). Does goal pursuit require conscious awareness? In R. M. Ryan (Ed.), The Oxford handbook of human motivation ( $2^{\text {nd }}$ ed.). Oxford University Press.

Devonport, T. J., \& Lane, A. M. (2013). Emotions and emotion regulation in a female couple undergoing In Vitro Fertilization treatment. Psychology, 4(6A), 25-33.

http://dx.doi.org/10.4236/psych.2013.46A1004 
Devonport, T. J., \& Lane, A. M. (2013). The utility of reflective practice during the provision of sport psychology support. In Z. Knowles., Gilbourne, D., Cropley, B., Dugdill, L. (Eds.), Reflective practice in the sport and exercise sciences: Contemporary issues. (pp. 174-182). Routledge.

Devonport, T. J., Lane, A. M., \& Lloyd, J. (2011). Keeping your cool: A case study of a female explorer's solo North Pole expedition. Journal of Human Performance in Extreme Environment, 22, 333337. https://doi.org/10.1016/i.wem.2011.07.003

Gailliot, M.T., Baumeister, R.F., DeWall, C.N., Maner, J.K., Plant, E.A., Tice, D.M., (2007). Self-control relies on glucose as a limited energy source: Willpower is more than a metaphor. Journal of Personality and Social Psychology, 92, 325-336. https://doi.org/10.1037/0022-3514.92.2.325

García-Buades, M.E., Peiró, J.M., Montañez-Juan, M.I., Kozusznik, M.W., \& Ortiz-Bonnín, S. (2020). Happy-Productive Teams and Work Units: A Systematic Review of the 'Happy-Productive Worker Thesis'. International Journal of Environment Research and Public Health 2020, 17, 69. https://doi.org/10.3390/ijerph17010069

Gross, J. J. (2011). The future's so bright, I gotta wear shades. Emotion Review, 3, 212-216. https://doi.org/10.1177\%2F1754073910361982

Gross, J. J., \& Feldman Barrett, L. (2011). Emotion generation and emotion regulation: One or two depends on your point of view. Emotion Review, 3, 8-16. https://doi.org/10.1177\%2F1754073910380974

Gross, J. J., \& Thompson, R. A. (2007). Emotion regulation: Conceptual foundations. In J. J. Gross (Ed.), Handbook of emotion regulation (pp. 3-26). The Guilford Press.

Han, C. S. Y., Parsons-Smith, R.L., \& Terry, P. C. (2020). Mood profiling in Singapore: Cross-cultural validation and potential applications of mood profile clusters. Frontiers in Psychology, 11, 665. https://doi.org/10.3389/fpsyg.2020.00665

Hanin, Y. L. (2010). Coping with anxiety in sport. In A. R. Nicholls (Ed.), Coping in sport: Theory, methods, and related constructs (pp. 159-175). Nova Science.

Harley, J. M., Pekrun, R., Taxer, J. L., \& Gross, J. J. (2019) Emotion regulation in achievement situations: An integrated model. Educational Psychologist, 54, 2, 106-126. https://doi.org/10.1080/00461520.2019.1587297

Inzlicht, M., \& Friese, M. (2019). The past, present, and future of ego depletion. Social Psychology, 50, 370-378. https://doi.org/10.1027/1864-9335/a000398

Karageorghis, C. I., Terry, P. C., Lane, A. M., Bishop, D. T., \& Priest, D.L (2011). The BASES Expert Statement on the use of music in exercise. The Sport and Exercise Scientist, 28, 18-19. http://www.bases.org.uk/Music-in-Exercise

Koole, S. L. (2009). The psychology of emotion regulation: An integrative review. Cognition \& Emotion, 23, 4-41. https://doi.org/10.1080/02699930802619031

Lahart, I., Darcy, P., Gidlow, C., \& Calogiuri, G. (2019). The effects of green exercise on physical and mental wellbeing: A systematic review. International Journal of Environmental Research and Public Health, 16(8), 1352. http://dx.doi.org/10.3390/ijerph16081352

Lane, A. M. (2006). Reflections of professional boxing consultancy. Athletic Insight, 3.

Lane, A. M. (2006). Ultra-endurance psychology - preparing for the challenge of the Sahara. Peak Performance.

Lane, A. M. (2012a). I want to perform better: so how should I feel? Polish Psychological Bulletin, 44(2), 130-136. https://doi.org/10.2478/ppb-2013-0015

Lane, A. M. (2012b). Can I run myself happy? In P. Totterdell, \& K. Niven (Eds.), Should I strap a battery to my head? (and other questions about emotion) (pp. 209-218). Peter Totterdell. 
Lane, A. M. (2020). Emotion and emotion regulation from the perspective of the practitioner. In M. C. Ruiz, \& C. Robazza. (Eds.), Feelings in sport: Theory, research, and practical implications for performance and well-being (pp. 187-197). Routledge.

Lane, A. M. (2020, April 23). Keeping your chin up by doing chin up...Day 33...33 chin ups!!! - Swimming issue!!!!!!! [video]. YouTube.

https://www.youtube.com/watch?v=tUMswd9piZw\&list=PLe4aB4CGzTI0q97i5Km3f9VPEhyXv NsNP\&index $=23$

Lane, A. M., Beedie, C. J., Devonport, T. J., \& Stanley, D. M. (2011). Instrumental emotion regulation in sport: Relationships between beliefs about emotion and emotion regulation strategies used by athletes. Scandinavian Journal of Medicine \& Science in Sports, 21, e445-e451. https://doi.org/10.1111/j.1600-0838.2011.01364.x

Lane, A. M., Beedie, C. J., Jones, M. V., Uphill, M., \& Devonport, T. J. (2011). The BASES expert statement on emotion regulation in sport. British Association of Sport and Exercise Sciences. https://www.bases.org.uk/BASES-Expert-Statements

Lane, A. M., Davis, P. A., \& Devonport, T. J. (2011). Emotion regulation during running: A test of interventions using music. Journal of Sports Science and Medicine, 10, 400-407. www.jssm.org/vol10/n2/22/v10n2-22pdf.pdf

Lane, A. M., \& Devonport, T. (2008). Cold comfort -- mind and matter training for the North Pole marathon. Peak Performance, (264), 5-7.

Lane, A. M., \& Godfrey, R. (2010). Emotional and cognitive changes during and post a near fatal heart attack and one-year after: A Case Study. Journal of Sports Science and Medicine, 9, 517-522.

Lane, A. M., Godfrey, R., Loosemore, M., \& Whyte, G. W (2014). Case studies in sport science and medicine. ISBN-13: 978-1499146943.

Lane, A. M., Stanley, D. M., \& Davis, P. A. (2014). Emotion regulation and emotional states: Effects of situational and individual factors. Current Advances in Psychology Research, 1, 26-32.

Lane, A. M., \& Terry, P. C. (2016). Online mood profiling and self-regulation of affective responses. In Schinke, R. J., McGannon, K. R., \& Smith, B. (Eds.), Routledge international handbook of sport psychology (pp. 324-334). Routledge.

Lane, A. M., \& Whyte, G. (2008). The loneliness of the long-distance swimmer. Peak Performance, (256), $1-4$.

Lane, A. M., Wilson, M. G., Whyte, G. P., \& Shave, R. (2011). Physiological correlates of emotionregulation during prolonged cycling performance. Applied Psychophysiology and Biofeedback, 36, 181-184. https://doi.org/10.1007/s10484-011-9156-z

Li, S., Wang, Y., Xue, J., Zhao, N., Zhu, T. (2020). The Impact of COVID-19 epidemic declaration on psychological consequences: A study on active Weibo users. International Journal of Environment Research in Public Health, 17, 2032.

Lloyd, J. C., Pedlar, C. R., Lane, A. M., \& Whyte, G. P. (2007). Mood state changes during an expedition to the south pole: a case study of a female explorer. In A. M. Lane (Ed.), Mood and human performance: Conceptual, measurement, and applied issues (pp. 221-236). Nova Science.

Maclntyre, T., Brick, N., Butler, C., Doherty, A., Lane, A. M., Morris, R., Murphy, C., Murphy, E., \& Rogan, M. (2020). Beyond the COVID-19 pandemic: Tips for players and athletes COVID-Recover: Connect-Outdoors-Visualize-Identify-Discover-Recover. https://www.psychologicalsociety.ie/source/Beyond\%20the\%20COVID19\%20Pandemic\%20Tips\%20for\%20Players\%20and\%20Athletes\%20COVID-RECOVER.pdf

Miles E., Sheeran, P., \& Webb, T. L. (2013). Meta-analytic estimates predict the effectiveness of emotion regulation strategies in the "real world": Reply to Augustine and Hemenover. Psychological Bulletin, 139(3), 730-734 
Nesse, R. M., \& Ellsworth, P. C. (2009). Evolution, emotions, and emotional disorders. American Psychologist, 64, 129-139.

Restubog, S. L. D., Carmella, A., C., \& Wang, L. (2020). Taking control amidst the chaos: Emotion regulation during the COVID-19 pandemic. Journal of Vocational Behavior, 119, 103440, https://doi.org/10.1016/j.jvb.2020.103440.

Roberts, R. J., \& Lane, A. M. (2021). Mood responses and regulation strategies used during COVID-19 among boxers and coaches. Frontiers in Psychology. https://doi.org/10.3389/fpsyg.2021.624119

Samson, A C., \& Gross, J. J. (2012) Humour as emotion regulation: The differential consequences of negative versus positive humour. Cognition and Emotion, 26, 375-384. https://doi.org/10.1080/02699931.2011.585069

Schimmenti, A., Billieux, J., \& Starcevic, V. (2020). The four horsemen of fear: An integrated model of understanding fear experiences during the COVID-19 pandemic. Clinical Neuropsychiatry, 17(2), 41-45. https://doi.org/10.36131/CN20200202

Schubert, T., Eloo, R., Scharfen, J., \& Morina, N. (2020). How imagining personal future scenarios influences affect: Systematic review and meta-analysis. Clinical Psychology Review, 75, 101811. https://doi.org/10.1016/i.cpr.2019.101811

Scientific Advisory Group for Emergencies (2020, June 26). Scientific evidence supporting the government response to coronovirus (COVID-19). https://www.gov.uk/government/collections/scientific-evidence-supporting-the-governmentresponse-to-coronavirus-covid-19

Stanley, D. M, Lane, A. M., Beedie, C. J., Devonport, T. J. (2012). I run to feel better; so why I am thinking so negatively. International Journal of Psychology and Behavioral Science, 2(6), 28-213. https://doi.org/10.5923/j.ijpbs.20120206.03

Stanley, D. M., Beedie, C. J., Lane, A.M., Friesen, A. P., \& Devonport, T. J. (2012). Emotion regulation strategies used by runners prior to training and competition. International Journal of Sport and Exercise Psychology, 10, 159-171. https://doi.org/10.1080/1612197X.2012.671910

Stevens, M. J., \& Lane, A. M. (2001). Mood-regulating strategies used by athletes. Athletic Insight, 3, 3. http://www.athleticinsight.com/Vol3lss3/MoodRegulation.htm

Thayer, R. E., Newman, J. R., \& McClain, T. M. (1994). Self-regulation of mood: Strategies for changing a bad mood, raising energy, and reducing tension. Journal of Personality and Social Psychology, 67, 910-925. https://doi.org/10.1037/0022-3514.67.5.910

Terry, P. C., Dinsdale, S. L., Karageorghis, C. I., \& Lane, A. M. (2006). Use and perceived effectiveness of pre-competition mood regulation strategies among athletes. Australian Journal of Psychology, 12, 123-127.

Wegner, D. M. (1994). Ironic processes of mental control. Psychological Review, 101, 34-52.

Weilenmann, S., Schnyder, U., Parkinson, B., Corda, C., von Känel, R., \& Pfaltz, M. C. (2018). Emotion transfer, emotion regulation, and empathy-related processes in physician-patient interactions and their association with physician well-being: A theoretical model. Frontiers in Psychiatry, 9, 389. https://doi.org/10.3389/fpsyt.2018.00389

West, R., Michie, S., Rubin, G. J., \& Amlot, R. (2020). Applying principles of behaviour change to reduce SAR-CoV-2 transmission. Nature Human Behaviour, 4, 451-459. https://doi.org/10.1038/s41562-020-0887-9 
Lane

This Page is Intentionally Left Blank 
Chapter 9: Emotion Regulation During COVID-19

This Page is Intentionally Left Blank 
Lane

This Page is Intentionally Left Blank 